\title{
WINTER PHILOPATRY IN MIGRATORY WATERFOWL
}

\author{
GREGory J. ROBERTSON ${ }^{1,3}$ AND FRED COOKE ${ }^{1,2}$ \\ 'Department of Biological Sciences, Simon Fraser University, Burnaby, British Columbia V5A 1S6, Canada; and \\ 2Pacific Wildlife Research Centre, Canadian Wildlife Service, Pacific and Yukon Region, 5421 Robertson Road, Delta, \\ British Columbia V4K 3 Y3, Canada
}

\begin{abstract}
Philopatry in migratory species can apply to any location used during the annual cycle. The degree of philopatry influences the genetic structure of populations, but only at the stage of the annual cycle when pair formation and gene exchange occur. Because pair formation in birds typically occurs during the breeding season, most studies have focused on breeding-site philopatry. Waterfowl (Anseriformes) are an important exception to this pattern because pair formation often occurs during the winter months. Yet, surprisingly few studies have examined winter philopatry in waterfowl. To serve as an impetus for future research, we summarize published information on winter philopatry in waterfowl and examine these patterns in light of current hypotheses proposed to explain philopatric behavior. Our analyses indicate that geese, swans, and sea ducks show high levels of winter philopatry, with homing rates varying between 49 and $98 \%$ to small study areas. In contrast, return rates ( 0 to $20 \%$ ) and homing rates $(35$ to $85 \%$ ) to large study areas probably are comparatively lower for dabbling ducks and pochards. Unfortunately, detailed comparisons among groups are hindered by variation in the scale at which philopatric behavior is evaluated (ranging from $<1 \mathrm{~km}^{2}$ to $10^{5} \mathrm{~km}^{2}$ ), and by confounding of return rates with homing rates. Future studies of winter philopatry would benefit by the adoption of a more standardized methodology. Many of the hypotheses proposed to explain breeding philopatry apply equally well to winter philopatry. In particular, both genetic and ecological mechanisms may play a role in the evolution of philopatry to the wintering ground. Additional field studies are needed to test these hypotheses, and we suggest future directions for a more detailed examination of this neglected area of research. Received 9 September 1996, accepted 28 April 1998.
\end{abstract}

Philopatry has beEN DOCUMENTED in a variety of avian species (Greenwood and Harvey 1982, Rohwer and Anderson 1988). Natal philopatry occurs when a juvenile animal returns to breed at its place of birth, whereas breeding philopatry results when an animal returns to breed at the site of a previous breeding attempt (Greenwood 1980). The level of philopatry can have a significant influence on the genetic structure of populations. When there is little movement of individuals among populations, considerable genetic substructuring can arise (Rockwell and Barrowclough 1987, Chesser 1991). Consequently, philopatry can lead to increased isolation of populations, possibly leaving small populations more susceptible to local extinction (Levins 1970, Gadgil 1971).

Several hypotheses have been proposed to explain the adaptive significance of breeding philopatry in birds and mammals (e.g. Greenwood 1980, Johnson and Gaines 1990). How-

${ }^{3}$ Present address: Canadian Wildlife Service, 6 Bruce Street, Mount Pearl, Newfoundland A1N 4T3, Canada. E-mail: greg.robertson@ec.gc.ca ever, a focus on breeding philopatry may provide an incomplete understanding of the ecological and evolutionary forces influencing philopatric behavior. For example, migratory species use a variety of habitats during the annual cycle, including breeding, molting, wintering, and migratory stopover locations. Mortality can occur during any of these stages, and philopatry to these sites can have significant consequences for individual fitness and population regulation. In addition, the physical location where gene flow occurs (probably determined by the mating system and the location where pair bonds are formed) is the relevant location for evaluating the genetic consequences of philopatry.

Waterfowl (Anseriformes) represent a case in point. Breeding philopatry is female biased in migratory waterfowl, a pattern opposite to that in most birds (Greenwood and Harvey 1982, Clarke et al. 1997). As such, much attention has focused on this unusual pattern of sex-biased philopatry (Rohwer and Anderson 1988, Anderson et al. 1992). However, philopatry to the location where pair formation occurs may be 
more critical in understanding population structure. Unlike most birds, many species of waterfowl pair in the winter. Thus, patterns of gene flow and population structure may be defined during winter rather than the breeding season. Selection pressures leading to winter philopatry might differ substantially from those leading to breeding philopatry. Moreover, within species, selection on a particular pattern of sex bias in breeding philopatry could be very different from that acting on winter philopatry.

Several recent reviews have considered breeding philopatry in waterfowl (Rohwer and Anderson 1988, Anderson et al. 1992), but few studies have evaluated patterns of winter philopatry. In this paper, we summarize existing data on patterns of winter philopatry in waterfowl, review current hypotheses on philopatry with respect to winter philopatry in waterfowl, and outline future research needs.

\section{Patterns of Winter Philopatry in WATERFOWL}

Published data on winter philopatry (i.e. between-year site fidelity) were obtained for 19 species of waterfowl in four tribes (geese and swans [Anserini], dabbling ducks [Anatini], pochards [Aythyini], and sea ducks [Mergini]) from 28 studies. The study areas ranged from a single pond or field to large continental areas. We restricted our analyses mostly to published information.

Quantifying philopatry.-The quantification of philopatry has meaning only in the context of the area to which the animal returns. This could be defined as narrowly as a nest site or as broadly as a major subdivision of an entire geographic range. Clearly, the more narrowly the location is defined the lower the frequency of philopatry, all else being equal. This can make comparisons among studies difficult. Therefore, study area sizes were categorized on a logarithmic scale starting from $<1 \mathrm{~km}^{2},<10$, $<100, \ldots$, to $<10^{5} \mathrm{~km}^{2}$.

Return rates (i.e. the number of animals recaptured or resighted as a proportion of the total number of animals marked) are frequently used to quantify philopatry. However, return rate is a composite of the probabilities that a bird will: (1) survive to the following year (survival rate); (2) return to the study area, given that it is alive (homing rate); and ( 3 ) be recaptured or resighted (recapture rate), given that it is alive and has returned to the study area (Hestbeck et al. 1991, Ebbinge 1992). Homing rate provides a true index of philopatry. Unfortunately, as a composite probability, return rates from different studies seldom are comparable. Generally, the recapture/resighting rate is highly variable from one study to the next and depends on the study design and the nature of the animal. Annual survival rates can also vary considerably, ranging from 0.53 to 0.88 in geese and 0.32 to 0.76 in ducks (Johnson et al. 1992). Generally, younger birds have higher mortality rates than adults, and females have higher mortality rates than males (at least in ducks).

A method that estimates homing rate directly is to compare the number of birds that returns to a study site with the number that goes elsewhere. Therefore, homing rate is the number of birds returning to the study site divided by the total number of birds resighted anywhere. Because all the birds in the sample have survived, survival is not confounded in this method. The method assumes that the resighting rates at all of the study sites are similar, which may or may not be true. Generally, this method will overestimate homing rate if the effort to resight birds outside of the study area is low.

Another method of estimating levels of winter philopatry in waterfowl is to use data obtained from band reports of recovered (usually shot) birds. This method is similar to the method of using resightings to estimate homing rate. Homing rate is the ratio of the number of birds that were banded in one winter and recovered in a subsequent winter in the same area to the total number of birds recovered anywhere. To obtain the necessary number of recoveries, this method is useful only over a large geographic range. An implicit assumption in homing rates derived from recoveries is that hunting pressure and vulnerability are similar across the range of the species. If certain areas are more heavily hunted, more recoveries will come from that region due to higher mortality rather than to a propensity of birds to return to that area. Differences in the reporting rate between areas could bias estimates of homing rate in a similar way.

We consider return rates and homing rates 
separately (because return rate is a composite probability that includes homing rate). Whenever possible, we emphasize studies reporting homing rates in our comparisons because survival is not confounded in these values.

Patterns of winter philopatry.-Geese and swans showed high levels of winter philopatry. Homing rates varied from 49 to $98 \%$ (median $=$ $71 \%, n=25$; Table 1 ). Likewise, sea ducks had high return rates to small study areas. Given that return rates are a minimum estimate of homing rates, it would appear that sea ducks (at least Buffleheads [Bucephala albeola] and Harlequin Ducks [Histrionicus histrionicus]) show high levels of winter philopatry. For pochards, only data from Canvasbacks (Aythya valisineria) are available. Canvasbacks had relatively low return rates ( 3 to $19 \%$ ) to small study areas (Table 1). Return rates for dabbling ducks ranged from 0 to $10 \%$ (median $=3 \%, n$ $=9$; Table 1 ). Study areas tended to be very large (many were $10^{5} \mathrm{~km}^{2}$ ). The proportion of individuals recovered in the same area of banding (homing rate) varied from 35 to $85 \%$ with a median of $58 \%$, except for Northern Pintails (Anas acuta), which ranged down to $5 \%(n=21$; Table 1).

Interpretation of patterns.-Although a considerable number of studies report indices of winter philopatry, these data are very difficult to compare in a meaningful way because the size of the study areas varies considerably. Moreover, return rates to an area of $10^{5} \mathrm{~km}^{2}$ are not very instructive in determining whether an individual is philopatric. The utility of return rates is also highly questionable, and comparing return rates across studies is difficult to justify. Given the large amounts of heterogeneity in these data, are they comparable in any way?

The data allow us to make some coarse comparisons among taxa, given certain assumptions. Geese and swans show high homing rates to relatively small geographic areas (1 to $10 \mathrm{~km}^{2}$ ), although they may use more than one wintering area in a season (Percival 1991, Fox et al. 1994). Dabbling ducks also show relatively high homing rates, yet the study areas are 100 to 1,000 times larger than those for geese and swans. Assuming that homing rates increase as the size of the study area increases, dabbling ducks show a lower homing rate than geese and swans to areas of similar size. Only return rates are available for the other duck species. Return rates are low for pochards and dabbling ducks and relatively high for sea ducks. The size of the study areas for pochards $\left(<1 \mathrm{~km}^{2}\right)$ is much smaller than for dabbling ducks $\left(10^{4}\right.$ to $\left.10^{5} \mathrm{~km}^{2}\right)$. Assuming that survival and recapture rates are similar for both groups of ducks, and that return rates increase with the size of the study area, then sea ducks and possibly Canvasbacks have higher homing rates than dabbling ducks. Survival rates of diving ducks are slightly higher than, or similar to, those of dabbling ducks (Johnson et al. 1992), so major differences in survival are unlikely to explain the differences in homing rates. It is unknown whether recapture rates are similar among studies.

A general conclusion that can be drawn from these data is that philopatry is not absolute to small geographic areas for any species. Although philopatry in geese and swans is very high, even small numbers of individuals moving among populations are sufficient to disrupt genetic isolation (Rockwell and Barrowclough 1987). Most species of dabbling ducks do not appear to be philopatric in a general sense, except perhaps at the flyway level. Thus, it is highly unlikely that genetic isolation occurs in any wintering population of dabbling ducks.

\section{A Review of Hypotheses And Mechanisms}

Two main sets of hypotheses have been proposed to explain the evolution of philopatric behavior (Weatherhead and Forbes 1994). The ecological (or somatic) set proposes that individuals return to familiar sites in order to take advantage of prior knowledge of the area. The genetic set posits that philopatry enables individuals to mate with partners with which they share a specific level of genetic relatedness.

Ecological mechanisms. - A number of hypotheses fall within an ecological or somatic benefit framework. All of these models predict that philopatric individuals have higher lifetime reproductive success than dispersers. Quantifiable benefits of philopatry should be apparent in the current generation.

Individuals that return to the same region year after year will become familiar with the area and should use this knowledge to their advantage. Philopatric individuals have a selective advantage over dispersers because they are not continually confronted with novel environ- 


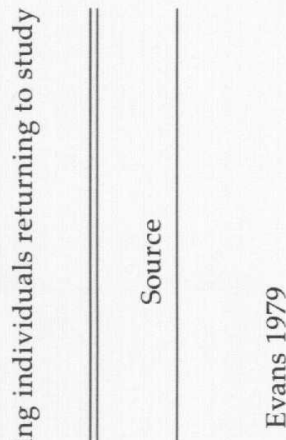

$\frac{\infty}{\stackrel{\infty}{a}}$

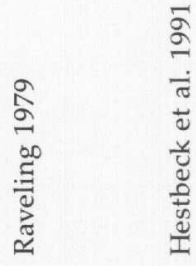

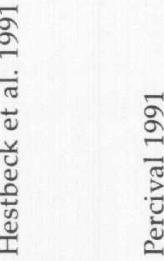

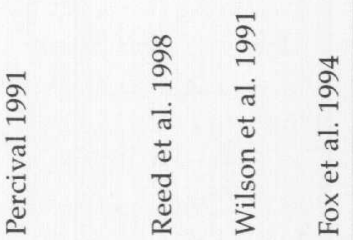

manintano

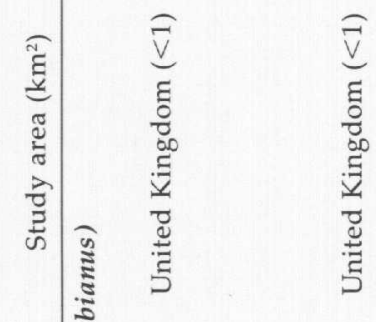

5
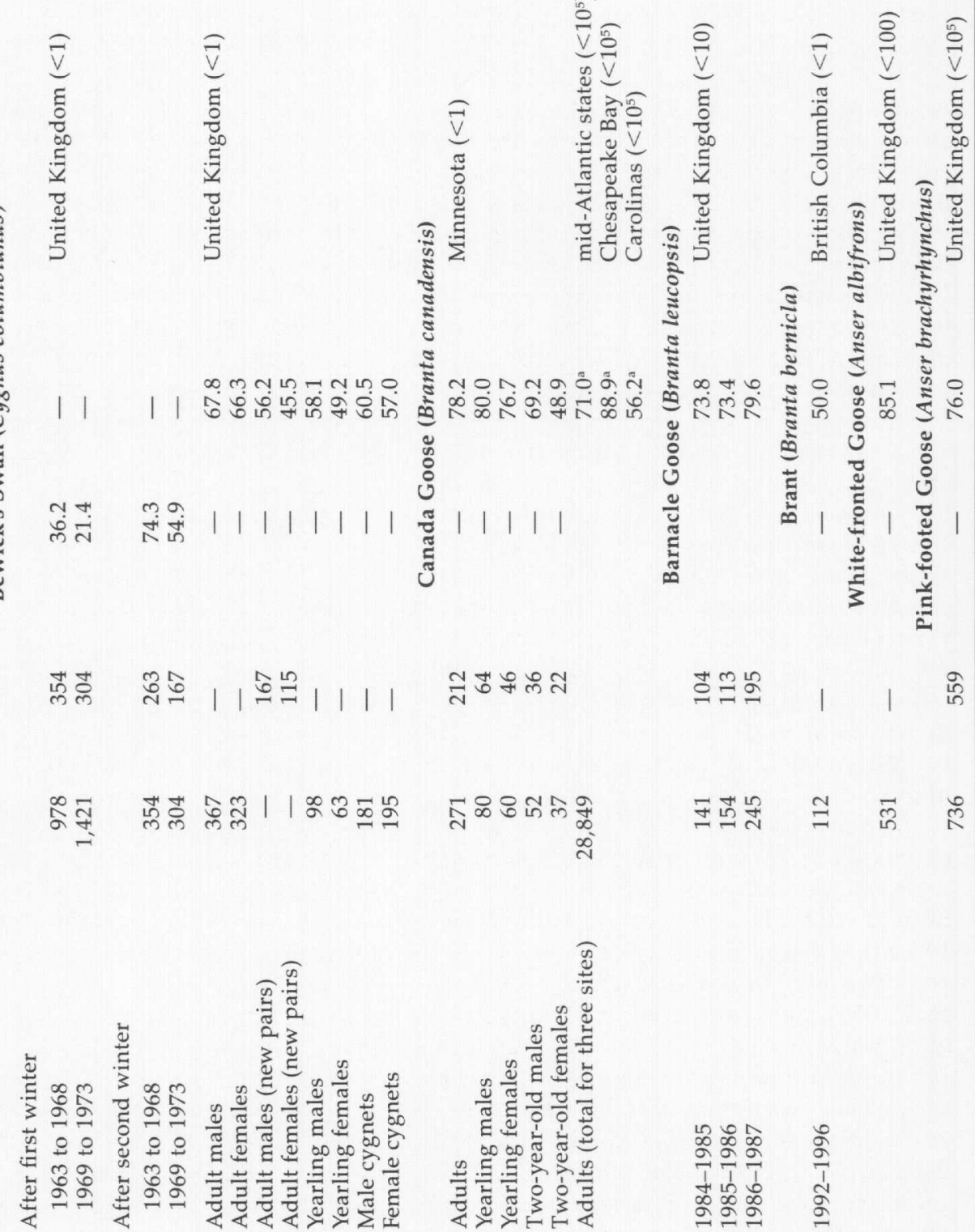

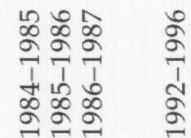




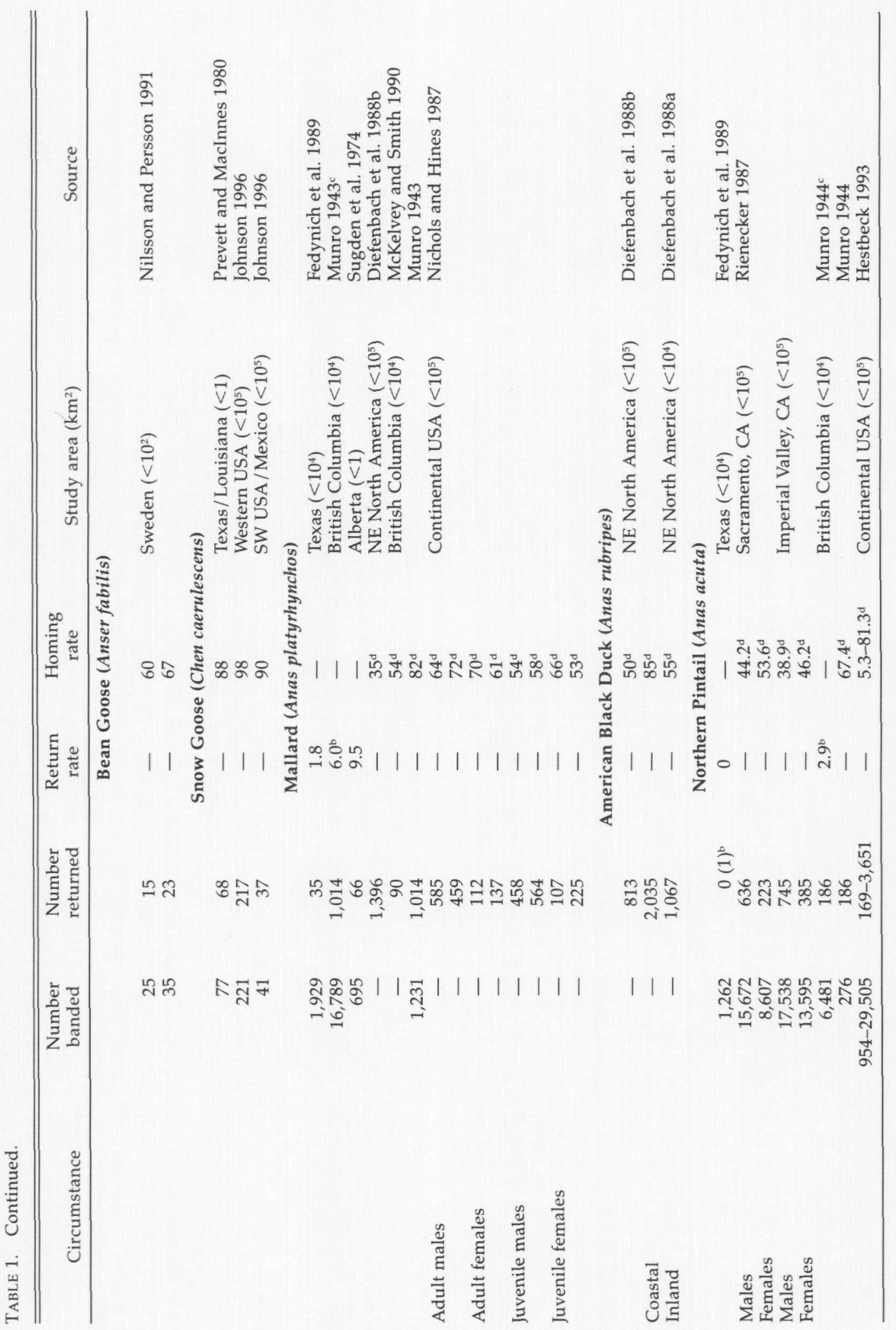




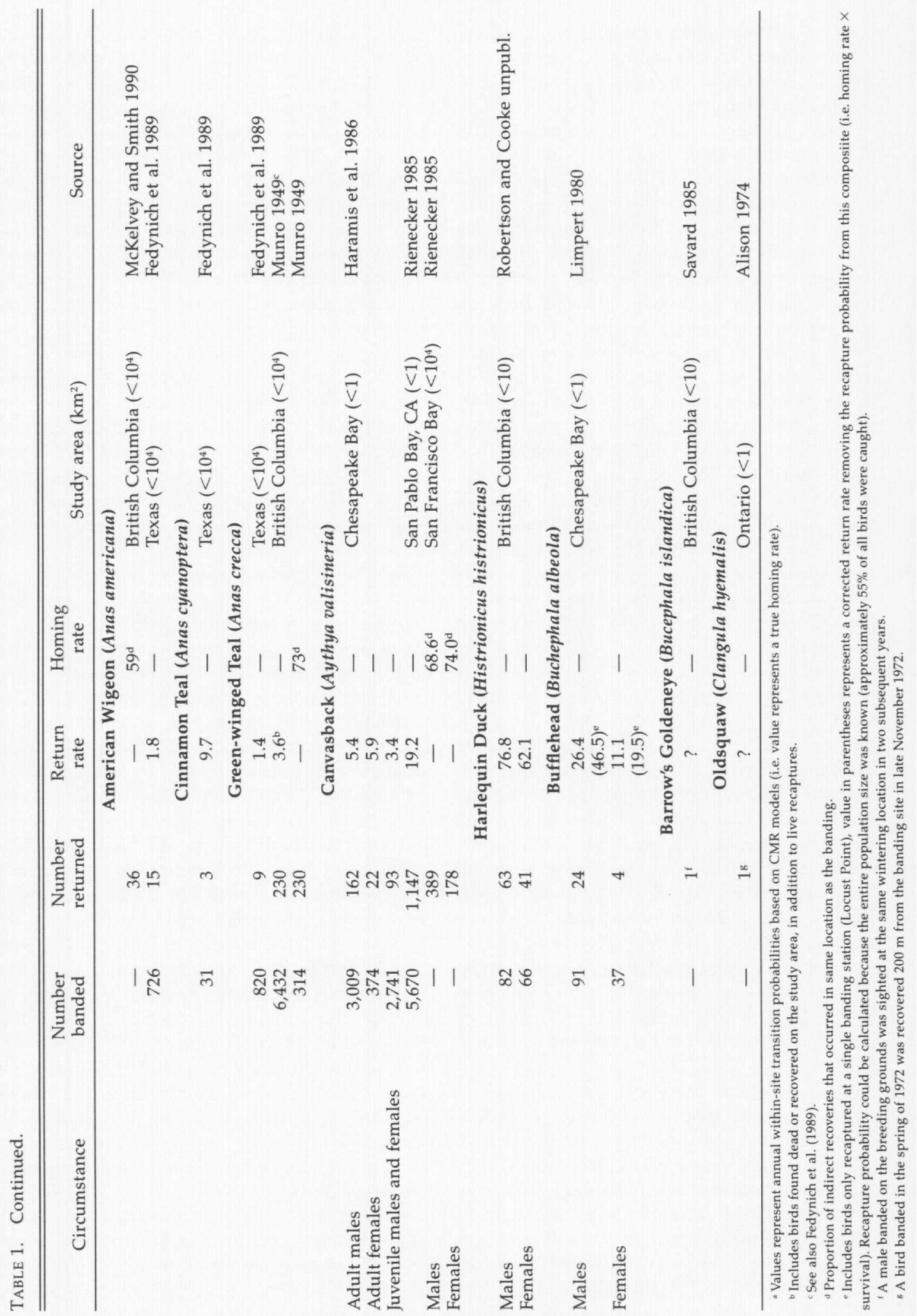


ments. Potential benefits include knowledge of patchy food resources and the locations of conspecifics, predator refugia, and predator movements and habits.

This "local-knowledge" hypothesis is commonly invoked to explain the high levels of breeding philopatry in female waterfowl (Rohwer and Anderson 1988). However, similar benefits can be realized by individuals that are philopatric to a wintering area. Individuals that return to a wintering location may be able to use their local knowledge to avoid predators and exploit food resources, thereby increasing their overwinter survival. Good foraging conditions on the wintering grounds can increase the reproductive success of females in the subsequent breeding season (Ankney and MacInnes 1978, Nichols and Hines 1987, Raveling and Heitmeyer 1989). Moreover, males and females in good condition pair earlier than those in poor condition (Brodsky and Weatherhead 1985, Hepp 1988, Pattenden and Boag 1989). This allows individuals in good condition to obtain a mate that is also in good condition (Heitmeyer 1995). Additionally, if philopatric individuals have local knowledge about where conspecifics tend to congregate, they may have an advantage when trying to find a suitable mate.

The social-cohesion hypothesis proposes that philopatry has evolved as a mechanism for individuals to maintain social bonds with conspecifics. Maintaining a cohesive family unit might be one reason for individuals to keep social bonds intact. In species with long-term pair bonds and extended parental care (i.e. geese and swans), individuals that are separated would be able to reunite at a common wintering ground. Raveling (1969) suggested that one function of the use of traditional roosting sites by Canada Geese (Branta canadensis) was to enable family groups that had become separated to reunite.

Another version of a social-cohesion hypothesis is related to mating systems. Species that have long-term pair bonds but do not remain together for the entire year can reunite if they share a common wintering ground. This may be most prevalent in sea ducks in which males leave the breeding grounds while their mates are incubating. Barrow's Goldeneyes (Bucephala islandica; Savard 1985), Buffleheads (Gauthier 1987), Oldsquaws (Clangula hyemalis; Alison
1975), Common Eiders (Somateria mollissima; Spurr and Milne 1976), and Harlequin Ducks (Bengtson 1972) have been seen with the same mate on the breeding grounds in subsequent years (see also Anderson et al. 1992). Direct observations of pairs reuniting on the wintering grounds occur for Common Eiders (Spurr and Milne 1976), Barrow's Goldeneyes (Savard 1985), and Harlequin Ducks (Gowans et al. 1997). Males that mate with the same female should follow her year after year to her natal breeding grounds. Male sea ducks show high levels of breeding philopatry, with levels approaching that of females (Anderson et al. 1992). In these species, philopatry to a common wintering area may have evolved to allow individuals to reunite and obtain the benefits of retaining the same mate (see Black 1996). However, it is also possible that winter philopatry in this group evolved for other reasons (i.e. pair reunion may be a consequence, rather than a cause, of winter philopatry).

Genetic mechanisms.--Individuals that mate with close relatives may suffer from inbreeding depression (Greenwood et al. 1978). Conversely, individuals that mate with unrelated individuals may suffer reduced fitness owing to the breakup of coadapted gene complexes. Theoretically, a level of inbreeding should evolve that maximizes individual fitness (i.e. optimal outbreeding; Bateson 1983, Greenwood 1987) by allowing gene combinations that are particularly adaptive at a local site to remain together (i.e. optimal inbreeding; Shields 1982, 1983).

Shields (1982, 1983) noted that waterfowl present a potential problem to this interpretation because a female's breeding area often is far away from her mate's natal area (Rohwer and Anderson 1988, Anderson et al. 1992). This introduces substantial amounts of gene flow among subpopulations (Cooke et al. 1975, Rockwell and Barrowclough 1987), suggesting that optimal inbreeding would be difficult to achieve in waterfowl. Shields $(1982,1983)$ noted that waterfowl pair on the wintering grounds and that the arguments still could be valid if populations were isolated on the wintering grounds.

Rhodes et al. (1993) documented low levels of genetic substructuring in American Wigeons (Anas americana) wintering in Texas. Novak et al. (1989) presented electrophoretic data suggesting that Brant (Branta bernicla) wintering 
on the eastern coast of North America show some level of local philopatry, although the magnitude was small. The presence of a variety of races in many species of geese also suggests that some populations are genetically isolated (Owen 1980, Van Wager and Baker 1986). However, evidence for genetic substructuring cannot be used to support or reject a genetically based hypothesis for the evolution of philopatry. If philopatry has evolved for purely somatic reasons, some level of genetic substructuring will arise as a consequence, rather than a cause, of philopatry.

Evidence of "short-stopping," where geese and swans winter farther north than normal when habitat conditions are favorable (Owen 1980, Hestbeck et al. 1991), would also seem to argue against a genetically based hypothesis for the evolution of philopatry. If winter philopatry serves to maintain the genetic isolation of a flock, then birds should always return to the same wintering grounds. However, if movements of flocks involve the same birds every time (see Percival 1991), genetic isolation of flocks would be maintained. In this case, philopatry would maintain the social integrity of flocks rather than their isolation. Observations of Snow Geese (Chen caerulescens), however, indicate that flock integrity is not maintained on the wintering grounds and that interchanges of individuals among flocks are frequent (Schroer and Chabreck 1974).

Some species of ducks segregate sexually on the wintering grounds, including most pochards, some sea ducks, and some dabblers. Generally, higher proportions of males are found in more northerly locations (e.g. Owen and Dix 1986, Carbone and Owen 1995). Local sexual segregation of species has also been documented (Nichols and Haramis 1980). Philopatry to areas in which pairing does not occur cannot be explained by genetic mechanisms. Thus, if philopatry to wintering locations occurs even when the sexes are segregated, hypotheses that are not genetically based must be sought.

For a genetic model to provide an adaptive explanation for the evolution of philopatry in waterfowl, a mechanism must exist for juveniles to obtain mates at the same location as their parents. Such a mechanism exists for geese and swans because parental care is extended such that broods follow their parents to the wintering grounds. However, similar mechanisms do not exist for most ducks; broods are usually abandoned by the female parent before the young depart for the wintering grounds. For optimal inbreeding hypotheses to be relevant, juvenile ducks must be able to "home" to a wintering location where they have never been. Young birds conceivably could migrate on their own and attempt to find their parents on the wintering grounds. In other bird species, mechanisms have evolved so that naive birds migrate to suitable wintering quarters even in the absence of their parents (Berthold 1996). Evidence from Mallards (Anas platyrhynchas) and American Black Ducks (Anas rubripes) suggests that juveniles associate with adults that migrate later than their parents (probably from more northerly locations). Juveniles subsequently migrate south with these unrelated adults and incorporate into flocks with them (Bellrose and Crompton 1970, Hopper et al. 1978, Nichols and Hines 1987). Additionally, individuals of some duck species are highly mobile in response to poor weather conditions (Bennett and Bolen 1978, Nichols et al. 1983, Jorde et al. 1984), further disrupting flock integrity. Thus, the likelihood of juvenile dabbling ducks joining the same wintering flocks as their parents is low.

Sex biases in philopatry.-Sex biases in winter philopatry can evolve for a number of reasons, once again classified as ecologically and / or genetically based models. For the ecologically based models, the somatic advantages of philopatry versus dispersal are different for each sex. These advantages can be based on natural selection pressures (e.g. different ecological requirements for each sex) or sexual selection pressures (e.g. the mating system favors different patterns of philopatry in the two sexes). For genetically based arguments, it is assumed that philopatry is advantageous for both sexes, but at the cost of extensive inbreeding. Slight differences in the ecological advantages of philopatry for one or the other sex will predict which sex will be more likely to disperse.

In general, male birds are more philopatric than females, both in terms of natal and breeding philopatry (Greenwood 1980, Greenwood and Harvey 1982, Clarke et al. 1997). Males tend to be the sex that defends a breeding territory. Presumably, local knowledge confers advantages to philopatric males over their po- 
tential competitors. Mobile females are then able to choose the highest-quality male and / or territory for breeding (somatic reasons), or disperse to avoid high levels of inbreeding (genetic reasons; Motro 1991). When males can economically defend an essential resource, male-biased philopatry should predominate. If males cannot defend a critical resource and the number of females is limited (or females vary in quality), a mate-defense mating system should evolve (Emlen and Oring 1977) and female-biased philopatry is predicted (Greenwood 1980, Greenwood and Harvey 1982).

Dabbling ducks form new pair bonds each year (Bellrose 1980; but see Losito and Baldassarre 1996). Male dabbling ducks engage in active courtship of females during the winter season, the exact timing depending on the species (Hepp and Hair 1983, Rohwer and Anderson 1988). Male ducks generally form a hierarchy among themselves before pair formation, and females tend to choose the highest-ranking males first (Hepp 1988, McKinney 1992, Oring and Sayler 1992). A significant male bias in most duck populations results in females being the limiting sex (Bellrose et al. 1961). The mating system in dabblers is based on mate choice, and no defensible resources are involved. In this case, female-biased philopatry is expected to evolve because females are free to stay in familiar habitats, whereas males that are unsuccessful in finding a mate must disperse to find available females (Greenwood 1980).

Dispersal is male biased in some ducks, especially in juveniles. In two California sites, male Northern Pintails had lower recovery rates $\left(\chi^{2}\right.$ tests, $\left.P<0.001\right)$ in the area they were banded than did females (based on data in Rienecker 1987). Juvenile male Green-winged Teal (Anas crecca) banded at a Texas site during winter were 4.2 times more likely to be recovered outside of the area than were adults (Baldassarre et al. 1988) and also dispersed more than juvenile females (Baldassarre et al. 1988). Juvenile male Mallards had a lower chance than adult males of being recovered in the area where they were originally banded (Nichols and Hines 1987).

In geese and swans, family groups migrate together to the wintering grounds. During winter, social interactions in goose and swan flocks are common, and dominance hierarchies are established (Raveling 1970, Owen 1980).
Pairs with broods rank highest in the hierarchy followed by pairs without broods and finally single birds (Raveling 1970, Lamprecht 1986, Black and Owen 1989). Families with high social status tend to feed more and win more encounters with other families (Scott 1980a, Black and Owen 1989). The male largely determines the social status of a pair (Raveling 1970, Scott 1980b, Lamprecht 1986). If the male's defense of the brood during winter is important, a young male may be at a selective advantage to return to a familiar area. This knowledge may help to ensure the survival of his brood and mate over the winter. Thus, in geese and swans, male-biased philopatry may result from extended parental care on the wintering grounds and the advantages for dominant males in bringing their mates and broods to a familiar area.

Rees (1987) found that new pairs of Bewick's Swans (Cygnus bewickii) moved to the previous wintering ground of the male. Males initiated local movements in the fall and on the wintering grounds. In spring, females initiated movements toward the breeding grounds. Yearling male Bewick's Swans had a higher return rate than females to their first wintering grounds (marginally significant; Rees 1987). Two-yearold male Canada Geese had higher return rates than females to a roosting site, but yearlings and adults did not show any sex biases in homing rate (Raveling 1979). Raveling (1979) suggested that the female follows the male to his wintering ground once a pair bond is established.

In species where pairing takes place very early in the winter, it may not be advantageous for unpaired males to disperse and attempt to find a mate, because all females in the population will be paired. This would result in equal rates of philopatry between the sexes, as seen in American Black Ducks (Diefenbach et al. 1988a). A similar outcome might be expected if pairing is highly synchronous across the entire range of a species.

Most sex-biased philopatry in geese and swans is restricted to younger or newly paired birds, as noted above (Raveling 1979, Rees 1987). No evidence exists for sex-biased winter philopatry in pochards and sea ducks (e.g. Limpert 1980, Nichols and Haramis 1980, Rienecker 1985, Haramis et al. 1986). Male Harlequin Ducks may have higher return rates than females (Fisher's exact test, $P=0.07$; Rob- 
ertson and Cooke unpubl. data); however, males that are unsuccessful in finding a mate tend to leave the wintering grounds (Robertson and Cooke unpubl. data).

In many species of ducks, males winter farther north than females. Pair formation can occur on the breeding grounds, as in Ruddy Ducks (Oxyura jamaicensis), but most species that exhibit sexual segregation during winter tend to pair in the spring (Weller 1965, Rohwer and Anderson 1988). Philopatry in the two sexes may or may not be different depending on the mechanism of sexual segregation. If females attempt to winter in northern areas with males, but are excluded due to male dominance, female-biased dispersal might result. Males have been shown to be behaviorally dominant to females on the wintering grounds (Choudhury and Black 1991). Alternatively, sex-biased philopatry would not be expected if females immediately migrate to marginal habitats or to more southern latitudes than males. Hypotheses suggesting that sexual segregation is based on sex-specific habitat or physiological requirements (see Myers 1981) also predict no sex bias because females and males would be philopatric to their respective and separate wintering grounds.

\section{Future Directions}

Standardized data collection.-All of the studies considered in this review obtained estimates of philopatry from individually marked birds. Obviously, continued use of marked individuals, ideally over a long period of time, is the only way to obtain the data necessary to test hypotheses related to philopatry. For comparisons among studies, better metrics of philopatry need to be established. The reporting of return rates should be strongly discouraged because little useful information can be extracted from such data. Homing rates provide a better index of philopatry, and the best method for estimating homing rates is with capture-markrecapture techniques that estimate survival rates, recapture rates, and homing rates simultaneously (e.g. Hestbeck et al. 1991, Lebreton et al. 1992, Nichols et al. 1993).

A further refinement in study design might be to standardize the minimum distance (or preferably, area) within which an individual is considered philopatric. We suggest reporting on a logarithmic scale (as in this review) to facilitate comparisons with other studies. Instead of reporting a single rate, a series of homing rates could be reported assuming the study area is $1 \mathrm{~km}^{2}, 10 \mathrm{~km}^{2}, \ldots, 10^{5} \mathrm{~km}^{2}$. Smaller ranges could be used for species that do not move widely. Studies that compare philopatry patterns within populations at different spatial scales would be especially valuable.

Taxonomic gaps. - The data available on philopatry in geese and swans are reasonably good. Although we obtained information from a number of studies of dabbling ducks, the utility of these data is questionable. This is not to say that these studies were done poorly; rather, it appears to be more difficult to obtain suitable data on homing rates for dabbling ducks than for geese and swans. As is generally true for most aspects of waterfowl biology, very little information is available for pochards, sea ducks, perching ducks, and other groups, which underscores the need to study winter philopatry in these species.

Sex biases. - Comparisons between sexes will provide insights into the role of mating systems and parental care in shaping patterns of winter philopatry in waterfowl. Waterfowl provide a rich opportunity for studies of winter philopatry because they use so many habitats and exhibit a diversity of mating systems (Oring and Sayler 1992). The study of breeding philopatry has been formalized into a theoretical framework for waterfowl (Rohwer and Anderson 1988). It is now time for winter philopatry to receive the same attention.

Because waterfowl pair on the wintering grounds, predictions based on the breeding season can be applied to the winter period. Thus, winter philopatry should be male biased if males can defend a critical resource and female-biased if males cannot defend a critical resource (Emlen and Oring 1977, Greenwood 1980). Research should focus on testing these predictions. For example, because goldeneyes are territorial on the wintering grounds (Savard 1988), male-biased winter philopatry should be the rule. Such a pattern would be particularly interesting in light of the fact that breeding philopatry in goldeneyes is female biased.

The frequency of pair reunion in sea ducks also will be a fruitful avenue of research. Although it is known that some pairs reunite on 
the wintering grounds, no information is available on the frequency of pair reunion. Comparisons of the level of winter philopatry and the frequency of pair reunion will provide insights into the importance of pairing with the same mate and the role of philopatry in facilitating pair reunion.

Importance of juveniles.-A critical gap in our knowledge is how juveniles become incorporated into wintering populations. Any test of a genetically based hypothesis of the evolution of philopatry requires information about juvenile settlement in wintering flocks. Even if adults are completely philopatric, low levels of juvenile dispersal will result in gene flow. Many taxa exhibit juvenile-biased dispersal from the breeding grounds (Greenwood and Harvey 1982), and it will be interesting to determine whether wintering waterfowl show the same pattern. The data for waterfowl suggest that juveniles are likely to disperse, but more information is needed.

Understanding patterns of juvenile dispersal is also essential to an examination of the relationship between philopatry and mating systems. In species that exhibit long-term pair bonds, only the younger age classes will be actively involved in mate choice. It is possible that a mating system has led to a strong male sex bias, but this bias could be masked entirely by equal philopatry levels exhibited by adults in long-term pair bonds.

Even if a species is serially monogamous, juveniles may be under different pressures from adults and thus display different levels of philopatry. Individuals of different condition or quality may exhibit different mating tactics (Austad 1984). For example, adult male dabbling ducks might be better suited to remain at a familiar place where they can obtain highquality resources and actively court females. Juvenile males may be better off to disperse in search of concentrations of unpaired females, or go to areas with no adult males to ensure their own survival. More sophisticated analyses of existing recovery data by sex and age classes could begin to address some of these questions.

Location and timing of pairing.-Surprisingly, pairing chronologies and the location of pairing are not well documented for many species. Even for the well-studied geese and swans, very little is known about the exact timing of pair-bond formation (Owen et al. 1988). Obviously, such information is critical for any test of a genetic hypothesis for philopatry. Indeed, pair-bond formation in geese and swans may differ geographically, and its exact timing and location are not well known for species that segregate during winter. Because the mating system is only a factor during pair formation itself, different explanations for philopatry may be necessary for different parts of a species' range. Finally, the widely held assumption that pairs observed in winter are maintained into the breeding period has very little direct supportive evidence. If pairs formed in winter are not relevant to gene exchange, then winter is no longer the appropriate time to test genetically based hypotheses.

Physical location and social cohesion.-Hypotheses for the evolution of philopatry based on the value of local knowledge are very different from those based on the maintenance of group cohesion. In the latter case, the environment the birds are in is not as important as the birds being together. Waterfowl are highly social, suggesting that group-living is important. Thus, philopatry in waterfowl simply may be a mechanism to ensure that individuals can readily find conspecifics. In species that tend to disperse, evidence that the same individuals move together to different wintering areas would provide evidence that social cohesion is important.

Habitat stability.-The role of habitat stability in shaping patterns of winter philopatry has not been addressed. Research questions along this line include: Do species that winter in predictable habitats tend to exhibit higher levels of philopatry, and does this pattern hold within species and between populations? Although habitat predictability is difficult to assess, some generalizations are possible. Marine habitats are considered to be more predictable than freshwater habitats. Shallow freshwater habitats are prone to freezing during cold spells, unlike marine waters. Relatively dry upland habitats are also reasonably stable. Whether patterns of philopatry follow this gradient would be a valuable direction of research.

As is usually the case, it is unlikely that any single hypothesis will explain the patterns of winter philopatry for all species of waterfowl. Undoubtedly, several hypotheses and mechanisms are responsible for shaping patterns of 
philopatry. Although our review has identified areas where some patterns are apparent, it is clear that much remains to be learned regarding the processes underlying winter philopatry in waterfowl.

\section{ACKNOWLEDGMENTS}

We thank J. Ball, E. Cooch, M. Coupe, S. Cullen, B. Ebbinge, B. Gurd, D. Lank, S. Ogle, E. Reed, B. Sandercock, C. Smith, T. Williams, and K. Woo for valuable comments on the manuscript. J. Eadie provided a wealth of suggestions, all of which enhanced the quality of the manuscript. The manuscript was prepared using the facilities of the CWS/NSERC Wildlife Ecology Research Chair, Simon Fraser University, and the Pacific Wildlife Research Centre (Canadian Wildlife Service, Pacific and Yukon Region). The senior author was supported by the British Columbia Waterfowl Society, the Institute for Wetland and Waterfowl Research, and Simon Fraser University.

\section{LITERATURE CiteD}

Alison, R. M. 1974. Oldsquaw homing in winter. Auk 91:188.

Alison, R. M. 1975. Breeding biology of the Oldsquaw (Clangula myematis). Ornithological Monographs No. 18.

Anderson, M. G., J. M. Rhymer, and F. C. Rohwer. 1992. Philopatry, dispersal and the genetic structure of waterfowl populations. Pages 365-395 in Breeding ecology and management of waterfowl (B. D. I. Batt, A. D. Afton, C. D. Ankney, D. H. Johnson, J. A. Kadlec and G. L. Krapu, Eds.). University of Minnesota Press, Minneapolis.

ANKNEY, C. D., AND C. D. MACINNES. 1978. Nutrient reserves and reproductive performance of female Lesser Snow Geese. Auk 95:459-471.

AUSTAD, S. N. 1984. A classification of alternative reproductive behaviors and methods for field-testing ESS models. American Zoologist 24:309-319.

BaLdassarre, G. A., E. E. Quinlan, AND E. G. BolEN. 1988. Mobility and site fidelity of Greenwinged Teal wintering on the Southern High Plains of Texas. Pages 483-493 in Waterfowl in winter (M. W. Weller, Ed.). University of Minnesota Press, Minneapolis.

BATESON, P. P. G. 1983. Optimal outbreeding. Pages 257-277 in Mate choice (P. Bateson, Ed.). Cambridge University Press, Cambridge, United Kingdom.

Bellrose, F. C. 1980. Ducks, geese and swans of North America. Stackpole Books, Harrisburg, Pennsylvania.

Bellrose, F. C., AND R. D. Crompton. 1970. Migrational behavior of Mallards and Black Ducks as determined from banding. Illinois Natural History Survey Bulletin 30:167-234.

Bellrose, F. C., T. G. SCOTt, A. S. HaWkins, AND J. B. Low. 1961. Sex ratios and age ratios in North American ducks. Illinois Natural History Survey Bulletin 27:391-474.

BENGTSON, S.-A. 1972. Breeding ecology of the Harlequin Duck (Histrionicus histrionicus) in Iceland. Ornis Scandinavica 3:1-19.

BenNetT, J. W., AND E. G. Bolen. 1978. Stress response in wintering Green-winged Teal. Journal of Wildlife Management 42:81-86.

BerTHOLD, P. 1996. Control of bird migration. Chapman and Hall, London.

BLACK, J. M. (Ed.). 1996. Partnerships in birds: The study of monogamy. Oxford University Press, Oxford.

BLACK, J. M., AND M. OWEN. 1989. Agonistic behaviour in Barnacle Goose flocks: Assessment, investment and reproductive success. Animal Behaviour 37:199-209.

BRodSKy, L. M., AND P. J. WeAtherheAD. 1985. Time and energy constraints on courtship in wintering American Black Ducks. Condor 87:33-36.

CARBONe, C., AND M. OWen. 1995. Differential migration of the sexes of Pochard Aythya ferina: Results from a European survey. Wildfowl 46:99108.

Chesser, R. K. 1991. Gene diversity and female philopatry. Genetics 127:437-447.

Choudhury, S., AND J. M. BLACK. 1991. Testing the behavioural dominance and dispersal hypothesis in Pochard. Ornis Scandinavica 22:155-159.

Clarke, A. L., B. -E. SæTHER, And E. RøSKaft. 1997. Sex biases in avian dispersal: A reappraisal. Oikos 79:429-438.

COOKe, F. C., C. D. Macinnes, J. P. Prevett. 1975. Gene flow between breeding populations of Lesser Snow Geese. Auk 92:493-510.

DiefenbaCh, D. R., J. D. Nichols, AND J. E. Hines. 1988a. Distribution patterns during winter and fidelity to wintering areas of American Black Ducks. Canadian Journal of Zoology 66:15061513.

DiefenbaCh, D. R., J. D. Nichols, and J. E. Hines. 1988b. Distribution patterns of American Black Duck and Mallard winter band recoveries. Journal of Wildlife Management 52:704-710.

EBBINGE, B. W. 1992. Regulation of numbers of darkbellied Brent Geese Branta bernicla bernicla on spring staging areas. Ardea 80:203-228.

EMLEN, S. T., AND L. W. ORING. 1977. Ecology, sexual selection and the evolution of mating systems. Science 197:215-223.

Evans, M. E. 1979. Population composition, and return according to breeding status, of Bewick's Swans wintering at Slimbridge, 1963 to 1976. Wild fowl 30:118-128.

FEDYNICH, A. M., R. D. GOdFREY, JR., AND E. G. BOL- 
EN. 1989. Homing of anatids during the nonbreeding season to the Southern High Plains. Journal of Wildlife Management 53:1104-1110.

Fox, A. D., C. Mitchell, A. Stewart, J. D. FletCher, J. V. N. TuRner, H. BOYD, P. SHIMMINGS, D. G. SAlmon, W. G. HAINES, and C. TOMLINSON. 1994. Winter movements and site-fidelity of Pink-footed Geese Anser brachyrynchus ringed in Britain, with particular emphasis in those marked in Lancashire. Bird Study 41:221-234.

GADGIL, M. 1971. Dispersal: Population consequences and evolution. Ecology 52:253-261.

GaUTHIER, G. 1987. Further evidence of long-term pair bonds in the ducks of the genus Bucephala. Auk 104:521-522.

Gowans, B., G. J, Robertson, And F. CoOke. 1997. Behaviour and chronology of pair formation by Harlequin Ducks Histrionicus histrionicus. Wildfowl 48:135-146.

GreenwoOd, P. J. 1980. Mating systems, philopatry and dispersal in birds and mammals. Animal Behaviour 28:1140-1162.

GREENWOOD, P. J. 1987. Inbreeding, philopatry and optimal outbreeding in birds. Pages 207-222 in Avian genetics (F. Cooke and P. A. Buckley, Eds.). Academic Press, London.

GreenwoOD, P. J., AND P. H. Harvey. 1982. The natal and breeding dispersal of birds. Annual Review of Ecology and Systematics 13:1-21.

Greenwood, P. J., P. H. Harvey, And C. M. Perrins. 1978. Inbreeding and dispersal in the Great Tit. Nature 271:52-54.

Haramis, G. M., J. D. Nichols, K. H. Pollock, AND J. E. HiNES. 1986. The relationship between body mass and survival of wintering Canvasbacks. Auk 103:506-514.

HeITMEYER, M. E. 1995. Influences of age, body condition, and structural size on mate selection by dabbling ducks. Canadian Journal of Zoology 73:2251-2258.

Hepp, G. R. 1988. Benefits, costs and determinants of dominance in American Black Ducks. Behaviour 109:223-234

HEPP, G. R., AND J. D. HAIR. 1983. Reproductive behavior and pairing chronology in wintering dabbling ducks. Wilson Bulletin 95:675-682.

HestBeCK, J. B. 1993. Overwinter distribution of Northern Pintail populations in North America. Journal of Wildlife Management 57:582-589.

Hestbeck, J. B., J. D. Nichols, And R. A. Malecki. 1991. Estimates of movement and site fidelity using mark-resight data of wintering Canada Geese. Ecology 72:523-533.

HOPPER, R. M., H. D. FUNK, AND D. R. ANDERSON. 1978. Age specificity in Mallards banded postseason in eastern Colorado. Journal of Wildlife Management 42:263-270.

JOHNSON, D. H., J. D. NiCHOLS, AND M. D. SCHWARTZ. 1992. Population dynamics of breeding water- fowl. Pages 446-485 in Breeding ecology and management of waterfowl (B. D. J. Batt, A. D. Afton, C. D. Ankney, D. H. Johnson, J. A. Kadlec and G. L. Krapu, Eds.). University of Minnesota Press, Minneapolis.

JoHnSON, M. L., AND M. S. Gaines. 1990. Evolution of dispersal: Theoretical models and empirical tests using birds and mammals. Annual Review of Ecology and Systematics 21:448-480.

JOHNSON, S. R. 1996. Staging and wintering areas of Snow Geese nesting on Howe Island, Alaska. Arctic 49:86-93.

Jorde, D. G., G. L. Krapu, R. D. Crawford, and M. H. HAY. 1984. Effects of weather on habitat selection and behavior of Mallards wintering in Nebraska. Condor 86:258-265.

LAMPRECHT, J. 1986. Structure and causation of the dominance hierarchy in a flock of Bar-headed Geese (Anser indicus). Behaviour 96:28-48.

Lebreton, J.-D., K. P. Burnham, J. Clobert, AND D. R. ANDERSON. 1992. Modeling survival and testing biological hypotheses using marked animals: A unified approach with case studies. Ecological Monographs 62:67-118.

Levins, R. 1970. Extinction. Pages 77-107 in Some mathematical problems in biology (M. Gesternhaber, Ed.). American Mathematical Society, Providence, Rhode Island.

LIMPERT, R. J. 1980. Homing success of adult Buffleheads to a Maryland wintering site. Journal of Wildlife Management 44:905-908.

Losito, M. P., and G. A. Baldassarre. 1996. Pairbond dissolution in Mallards. Auk 113:692-695.

MCKelveY, R., AND G. E. J. SMITH. 1990. The distribution waterfowl banded or returned in British Columbia, 1951-1985. Canadian Wildlife Service Technical Report Series No.79.

MCKINNEY, F. 1992. Courtship, pair formation, and signal systems. Pages 214-250 in Breeding ecology and management of waterfowl (B. D. J. Batt, A. D. Afton, C. D. Ankney, D. H. Johnson, J. A. Kadlec and G. L. Krapu, Eds.). University of Minnesota Press, Minneapolis.

Motro, U. 1991. Avoiding inbreeding and sibling competition: The evolution of sexual dimorphism for dispersal. American Naturalist 137: 108-115.

Munro, J. A. 1943. Studies of waterfowl in British Columbia. Mallard. Canadian Journal of Research (D) 21:223-260.

Munro, J. A. 1944. Studies of waterfowl in British Columbia. Pintail. Canadian Journal of Research (D) 22:60-86.

MunRo, J. A. 1949. Studies of waterfowl in British Columbia. Green-winged Teal. Canadian Journal of Research (D) 27:149-178.

MYERS, J. P. 1981. A test of three hypotheses for latitudinal segregation of the sexes in wintering 
birds. Canadian Journal of Zoology 59:15271534.

Nichol.s, J. D., C. Brownie, J. E. Hines, K. H. PolLOCK, AND J. B. HestBECK. 1993. The estimation of exchanges among populations or sub-populations. Pages 265-279 in Marked individuals in the study of bird populations (J.-D. Lebreton and P. M. North, Eds.). Springer-Verlag, Birkhäuser, Switzerland.

Nichols, J. D., and G. M. Haramis. 1980. Sex-specific differences in winter distribution patterns of Canvasbacks. Condor 82:406-416.

Nichols, J. D., AND J. E. Hines. 1987. Population ecology of the Mallard. VIIl. Winter distribution patterns and survival rates of winter-banded Mallards. United States Fish and Wildlife Service Resource Publication No. 162.

Nichols, J. D., K. J. Reinecke, And J. E. Hines. 1983. Factors affecting the distribution of Mallards wintering in the Mississippi Alluvial Valley. Auk 100:932-946

Nilsson, L., AND H. Persson. 1991. Site tenacity and turnover rate of staging and wintering Bean Geese Anser fabalis in southern Sweden. Wildfowl 42:53-59.

NovaK, J. M., L. M. SMITH, AND L. D. Vanglider 1989. Genetic variability within and among wintering populations of Brant. Journal of Heredity 80:160-163.

ORING, L. W., AND R. D. SAYLER. 1992. The mating systems of waterfowl. Pages 190-213 in Breeding ecology and management of waterfowl. (B. D. J. Batt, A. D. Afton, C. D. Ankney, D. H. Johnson, J. A. Kadlec and G. L. Krapu, Eds.). University of Minnesota Press, Minneapolis.

OWEN, M. 1980. Wild geese of the world. B. T. Batsford Limited, Fakenham, United Kingdom.

OWEN, M., J. M. BLACK, AND H. Liber. 1988. Pair bond duration and timing of its formation in Barnacle Geese (Branta leucopsis). Pages 23-38 in Waterfowl in winter (M. W. Weller, Ed). University of Minnesota Press, Minneapolis.

OWEN, M., AND M. Dix. 1986. Sex ratios in some common British wintering ducks. Wildfowl 37:104112.

Pattenden, R. K., And D. A. BoAG. 1989. Effects of body mass on courtship, pairing, and reproduction in Mallards. Canadian Journal of Zoology 67:495-501.

Percival, S. M. 1991. The population structure of Greenland Barnacle Geese Branta leucopsis on the winter grounds on Islay. Ibis 133:357-364.

Prevett, J. P., And C. D. Macinnes. 1980. Family and other social groups in Snow Geese. Wildlife Monographs No. 71.

Raveling, D. G. 1969. Preflight and flight behavior of Canada Geese. Auk 86:671-681.

RAVELiNG, D. G. 1970. Dominance relationships and agonistic behavior of Canada Geese in winter. Behaviour 37:291-319.

RavelinG, D. G. 1979. Traditional use of migration and winter roost sites by Canada Geese. Journal of Wildlife Management 43:229-235.

Raveling, D. G., AND M. E. Heitmeyer. 1989. Relationships of population size and recruitment of Pintails to habitat conditions and harvest. Journal of Wildlife Management 53:1088-1103.

ReEd, E. T., E. G. COOCH, R. I. Goudie, AND F. CoOKE. 1998. Site fidelity of Black Brant staging in the Strait of Georgia, British Columbia. Condor 100: 426-437.

ReEs, E. C. 1987. Conflict of choice within pairs of Bewick's Swans regarding their migratory movement to and from the wintering grounds. Animal Behaviour 35:1685-1693.

Rhodes, O. E., JR., L. M. SMITH, AND R. K. Chesser. 1993. Temporal components of genetic variation in migrating and wintering American Wigeon. Canadian Journal of Zoology 71:2229-2235.

RIENECKER, W. C. 1985. An analysis of Canvasbacks banded in California. California Fish and Game 71:141-149

RIENECKER, W. C. 1987. Migration and distribution of Northern Pintails banded in California. California Fish and Game 73:139-155.

ROCKWELL, R. F., AND G. F. BARROWClOUGH. 1987. Gene flow and the genetic structure of populations. Pages 223-255 in Avian genetics (F. Cooke and P. A. Buckley, Eds.). Academic Press, London.

ROHWER, F. C., AND M. G. ANDERSON. 1988. Femalebiased philopatry, monogamy, and the timing of pair formation in migratory waterfowl. Current Ornithology 5:187-221.

SAVARD, J.-P. L. 1985. Evidence of long-term pair bonds in Barrow's Goldeneye (Bucephala islandica). Auk 102:389-391.

SAVARD, J.-P. L. 1988. Winter, spring and summer territoriality in Barrow's Goldeneye: Characteristics and benefits. Ornis Scandinavica 19:119128.

SCHROER, J. D., AND R. H. ChabreCK. 1974. Dispersal and flock integrity of Snow Geese in Louisiana and Texas. Proceedings of the Annual Conference of the Southeast Association Game and Fish Commission 28:468-474.

ScoTT, D. K. 1980a. Functional aspects of prolonged parental care in Bewick's Swans. Animal Behaviour 28:938-952.

SCOTT, D. K. 1980b. Functional aspects of the pair bond in winter in Bewick's Swans (Cygnus columbianus bewickii). Behavioral Ecology and Sociobiology $7: 323-327$

SHIElDS, W. M. 1982. Philopatry, inbreeding and the evolution of sex. State University of New York Press, Albany.

SHIELDS, W. M. 1983. Optimal outbreeding and the 
evolution of philopatry. Pages 132-159 in The ecology of animal movement (I. R. Swingland and P. J. Greenwood, Eds). Clarendon Press, Oxford.

Spurr, E., AND H. MiLne. 1976. Adaptive significance of autumn pair formation in the Common Eider Somateria mollissima (L.). Ornis Scandinavica 7:85-89.

Sugden, L. G., W. J. Thurlow, R. D. Harris, and K. VERMEER. 1974. Investigations of Mallards overwintering at Calgary, Alberta. Canadian FieldNaturalist 88:303-311.

VAN WAGNer, C. E., AND A. J. BAKER. 1986. Genetic differences in populations of Canada Geese
(Branta canadensis). Canadian Journal of Zoology 64:940-947.

WeatherheAD, P. J., AND M. R. L. Forbes. 1994. Natal philopatry in passerine birds: Genetic or ecological influences? Behavioral Ecology 5:426433.

Wel.ter, M. W. 1965. Chronology of pair formation in some Nearctic Aythya (Anatidae). Auk 82:227235.

Wilson, H. J., D. W. NoRriss, A. W ALSh, A. D. Fox, AND D. A. STROUd. 1991. Winter site fidelity in Greenland White-fronted Geese Anser albifrons flavirostris, implications for conservation and management. Ardea 79:287-294.

Associate Editor: J. M. Eadie 